\title{
MODELING COARSE SAND TRANSPORT UNDER SKEWED OSCILLATORY FLOW USING A CFD-DEM APPROACH
}

\author{
Yashar Rafati, University of Delaware, yashar@udel.edu \\ Zhen Cheng, Woods Hole Oceanographic Institution, zcheng@whoi.edu \\ Xiao Yu, University of Florida, yuxiao03@ufl.edu \\ Tian-Jian Hsu, University of Delaware, thsu@udel.edu \\ Joseph Calantoni, Naval Research Laboratory. Joe.Calantoni@nrlssc.navy.mil
}

\section{INTRODUCTION}

Onshore/offshore sediment transport in the nearshore is an important mechanism driving the evolution of coastal morphology. The so-called sheet flow is a transport regime, in which the flow forces are intense such that a large amount of transport occurs in a concentrated layer near the bed. Onshore transport is often associated with flow skewness/asymmetry. In the nearshore zone, due to the bottom slope and wave shoaling, the wave velocity tends be onshore skewed before breaking in the surf zone. For breaking waves, the velocity asymmetry (or acceleration skewness) may also play a key role in determining net sediment transport. Understanding the net sediment transport rate in response to wave skewness/asymmetry is fundamental to a better prediction of sediment transport in regional scale morphodynamic models. In this study, we used an Euler-Lagrange two-phase model to study sheet flow transport of coarse sand under oscillatory flows subject to velocity/acceleration skewness.

\section{MODEL DESCRIPTION}

The open-source solver CFDEM-3.5.1 (Goniva et al., 2012) that couples fluid solver (OpenFOAM-2.4.x) with Discrete Element Method (DEM) solver (LIGGGHTS-3.6.0) was extended in this study for sediment transport. The soft-sphere model (e.g., Cundall \& Strack, 1979) was adapted for intergranular forces. The fluid phase was solved by RANS model similar to Cheng et al., 2017, where a modified k- $\varepsilon$ model is employed for turbulence closure. The fluid phase and sediment phase were coupled with drag force and pressure gradient force. The effect of turbulence on particle dispersion was added to the drag force by using an eddyinteraction model (EIM, Graham \& James, 1996). The EIM model has been demonstrated to have the capability of modeling turbulent suspension and sheet flow in steady flow (Cheng et al., 2018), and we further extend the model to study sheet flow under oscillatory flows.

\section{PRIMARY RESULTS}

Model validation was performed using the experimental data of O'Donoghue \& Wright (2004), where the sand is well-sorted with median grain diameter $0.51 \mathrm{~mm}$. The flow is a secondorder Stokes wave with maximum velocity magnitude of $\mathrm{U}_{\mathrm{m}}=1.5 \mathrm{~m} / \mathrm{s}$ and skewness $\mathrm{S}=0.63$ (Figure $1-\mathrm{a}$ ). Sediment concentration within the sheet flow layer at the flow peak shows a good agreement between the measured data and the model results (Figure 1-b). As a result of the onshore velocity skewness, the time averaged sediment transport rate predicted by the present model is $50 \mathrm{~mm}^{2} / \mathrm{s}$, which is close to the measured value of $44 \mathrm{~mm}^{2} / \mathrm{s}$. The model is further applied to study the effect of grain size distribution, as often found in natural sand bed. Figure 1-c shows the particle distribution after 5 waves. Even for this relatively narrow distribution, we can see vertical grading of sediment, i.e., larger (smaller) particles are preferentially exposed (armored) in the sand bed. Numerical experiments are carried out by turning off the EIM to eliminate turbulent suspension. Preliminary analysis suggests the hiding and exposure effects (e.g., van Rijn 2007) are different for bedload and suspended load transport.

We will carry out more comprehensive simulations with wider grain distributions and a range of velocity skewness and acceleration skewness. Furthermore, time-averaged transport rates will be compared with the practical sand transport formula proposed by van der A et. al., (2013).
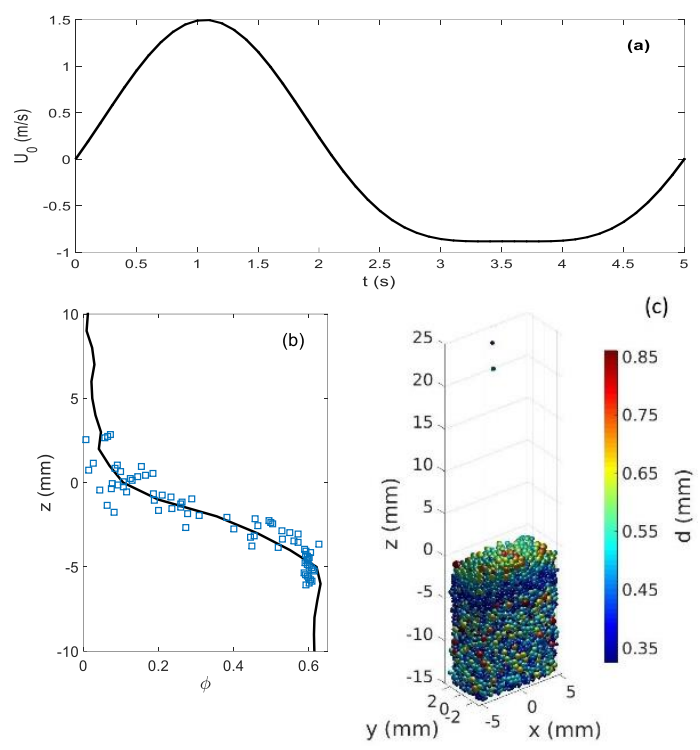

Figure 1: (a) Time series of free-stream velocity used in the experiment of O'Donoghue \& Wright (2004) and the present model. (b) Modeled (line) and measured (symbols) sediment concentration profile at flow peak. (c) A snapshot of sediment particles in the domain. The color of each particle represents its diameter.

\section{REFERENCES}

Cheng, Hsu, Calantoni (2017): SedFoam: A multi-dimensional Eulerian two-phase model for sediment transport and its application to momentary bed failure, Coastal Engineering, pp. 32-50.

Cheng, Chauchat, Hsu, Calantoni (2018): Eddy interaction model for turbulent suspension in Reynolds-averaged EulerLagrange simulations of steady sheet flow, Advances Water Resources, vol. 111, pp. 435-451.

Cundall, Strack (1979): A discrete numerical model for granular assemblies, vol. 29(1), pp. 47-65.

Goniva, Kloss, Deen, Kuipers, Pirker (2012), Influence of rolling friction on single spout fluidized bed simulation, Particuology, vol. 10(5), pp. 582-591.

Graham, James (1996): Turbulent dispersion of particles using eddy interaction models, International Journal of Multiphase Flow, vol. 22(1), pp. 157-175.

O'Donoghue, Wright (2004): Concentration in oscillatory sheet flow for well sorted and graded sands, Coastal Engineering, vol. 50, pp.117-138.

van der A, Ribbrink, van der Werf, O'Donoghue (2013): Practical sand transport formula for non-breaking waves and currents, Coastal Engineering, vol. 76, pp. 26-42.

van Rijn (2007): Unified view of sediment transport by currents and waves, J. Hydraulic Eng., vol. 133(7), pp. 761-775. 